\title{
COVID-19 and beliefs about tobacco use: an online cross-sectional study in Iran
}

\author{
Mohammad Ebrahimi Kalan ${ }^{1} \cdot$ Hassan Ghobadi ${ }^{2} \cdot$ Ziyad Ben Taleb $^{3} \cdot$ Davoud Adham $^{4} \cdot$ Caroline Cobb $^{5}$. \\ Kenneth D Ward ${ }^{6} \cdot$ Raed Behaleh $^{7} \cdot$ Mehdi Fazlzadeh $^{8,9}$
}

Received: 8 August 2020 / Accepted: 28 September 2020 / Published online: 7 October 2020

(C) Springer-Verlag GmbH Germany, part of Springer Nature 2020

\begin{abstract}
There is mixed evidence surrounding the relationship between tobacco use and COVID-19 infection/progression. The current study investigates beliefs and tobacco use behaviors and COVID-19 infection among a sample of smokers and never-smokers. Data were collected using an online survey distributed through Telegram, a cloud-based social media networking application in Iran from April 1 to May 31, 2020. The study participants included never-smokers $(n=511)$, current (past-month) waterpipe smokers $(n=89)$, current cigarette smokers $(n=158)$, and ex-smokers $(n=172)$. Multinomial logistic regression was used to compare tobacco use groups with never- smokers on beliefs, controlling for potential confounders. The study participants $(n=944)$ was mostly male (64\%), had $>$ high school education (76\%), and lived in an urban area (91\%), with mean \pm SD age of 35.3 \pm 10.8 . Key findings of this study are that compared with never-smokers: (1) cigarette smokers were less likely to believe that smoking cigarette can lead to spreading COVID-19; (2) waterpipe smokers were more likely to believe that smoking waterpipe at home was a safe practice, that waterpipe protects against COVID-19, and smoking waterpipe may lead to a more rapid recovery from COVID-19; (3) both waterpipe and cigarette smokers believed that using e-cigarettes in public places was a safe practice during the COVID-19 pandemic; and (4) more than half of the ex-smokers stopped smoking due to COVID-19 and most of them planned to continue abstaining from smoking after the pandemic. Our findings underscore the need to raise awareness about the unsupported claims of a lower hazard of using tobacco products or possible protective effects against COVID-19 and to promote cessation programs.
\end{abstract}

Keywords COVID-19 $\cdot$ Cigarette $\cdot$ Waterpipe $\cdot$ E-cigarettes $\cdot$ Smoking $\cdot$ Harm perceptions $\cdot$ Iran

\section{Introduction}

A growing debate about the potential link between COVID-19 severity and tobacco smoking is unfolding

Responsible Editor: Lotfi Aleya

Davoud Adham

davoudadham@gmail.com

Mehdi Fazlzadeh

m.fazlzadeh@gmail.com; m.fazlzadeh@arums.ac.ir

1 Department of Epidemiology, Robert Stempel College of Public Health, Florida International University, Miami, FL, USA

2 Department of Internal Medicine, Pulmonary Division, Faculty of Medicine, Ardabil University of Medical Sciences, Ardabil, Iran

3 Department of Kinesiology, College of Nursing and Health Innovation, University of Texas at Arlington, Arlington, TX, USA

4 Department of Public Health, School of Health, Ardabil University of Medical Sciences, Ardabil, Iran
(WHO 2020a). For example, a systematic review found lower smoking prevalence among patients hospitalized with COVID-19 in China compared with population smoking prevalence and hypothesized that nicotine-

5 Department of Psychology, Virginia Commonwealth University, Richmond, VA, USA

6 School of Public Health, University of Memphis, Memphis, TN, USA

7 School of Health Sciences, Baldwin Wallace University, Berea, $\mathrm{OH}$, USA

8 Department of Environmental Health, School of Health, Ardabil University of Medical Sciences, Ardabil, Iran

9 Department of Environmental Health, School of Health, Tehran University of Medical Sciences, Tehran, Iran 
through its immunomodulatory effects - might protect against COVID-19 (Farsalinos et al. 2020). However, a meta-analysis of 19 studies from China, the USA, and Korea concluded that tobacco smoking is a risk factor for the progression of COVID-19 (Patanavanich and Glantz 2020). On May 26, 2020, a scientific brief by the World Health Organization (WHO) concluded that "the available evidence suggests that smoking is associated with increased severity of disease and death in hospitalized COVID-19 patients" (WHO 2020a).

The risk of transmission of COVID-19 may be higher among waterpipe smokers given that this activity involves social gatherings, close contact among people who smoke waterpipe together, and sharing the same waterpipe in cafés or home environments (WHO 2020b). Waterpipe apparatus, particularly the mouthpiece and handle, are colonized by microbes and pose an infection risk (Altindis et al. 2020; Naddafi et al. 2019a). Additionally, waterpipe venues throughout the world tend to be densely occupied and poorly ventilated (Al Mulla et al. 2015; Cobb et al. 2013; Fazlzadeh et al. 2015; Naddafi et al. 2019c; Rostami et al. 2020), resulting in poor air quality (e.g., high levels of particulate matter, tobacco-specific nitrosamines, and polycyclic aromatic hydrocarbons) (Kumar et al. 2015; Naddafi et al. 2019b; Naddafi et al. 2019c; Rostami et al. 2019) and endangering both smokers and those exposed to secondhand smoke (Bhatnagar et al. 2019; El-Zaatari et al. 2015). Measures such as social distancing and educating the public about the possible link between smoking (cigarettes or waterpipe) and COVID-19 risk especially in countries with high smoking prevalence are essential to effectively respond to this pandemic. It is prudent to assert that now is the time to increase efforts to maximize smoking cessation and clean indoor air environment (particularly for waterpipe-serving venues) in the general population as a strategy to limit the COVID-19 pandemic.

In Iran, the prevalence of current (past-month) cigarette and waterpipe smoking is estimated to be $21.7 \%$ and $24.2 \%$ among males and $3.6 \%$ and $11.3 \%$ among females aged 15 years and older, respectively (Hessami et al. 2016; Moosazadeh et al. 2013). Iran is an epicenter of COVID-19 in the Middle East with a fairly high prevalence of smoking. Therefore, understanding beliefs among the general population (smokers and never-smokers) about how tobacco use may increase the risk of COVID-19 is crucial to inform the development of targeted prevention and cessation interventions. The current study surveyed a sample of never-smokers and smokers in Iran to ascertain beliefs and perceptions surrounding the use of different tobacco products and COVID-19 infection.

\section{Materials and methods}

\section{Study design}

An online survey was used to collect data on sociodemographic, tobacco use behaviors, and beliefs about the relationship between tobacco use and COVID-19 (see Table 1 for study questions). Data collection time was spanned from April 1 to May 31, 2020, by disseminating the questionnaire via Telegram - a mobile-based online social network - which is the most popular application (> 50 million users) for communicating in Iran (Ghaffari et al. 2017; Wikipedia 2020). The questionnaire was designed in an Iranian platform (Porsline; https://survey.porsline.ir), and one survey per IP address was allowed to avoid multiple submissions by one respondent using the same device (mobile or computer). The online survey link was shared on different public chat rooms with a minimum of 500 followers on Telegram. The survey was directed at smokers and never-smokers aged 15 years or older who completed the surveys anonymously after providing informed consent. The Ardabil University of Medical Sciences and Health Services' Institutional Review Board approved the study protocol.

Of the 946 individuals who responded to the online survey, 511 were never-smokers, 89 current (past-month) waterpipe smokers, 158 current cigarette smokers, 14 current dual(waterpipe and cigarette) smokers, 2 current electronic cigarettes (e-cigarette) users, and 172 ex-smokers (cigarette, waterpipe, or dual use who quit during the 3 months preceding the survey). We excluded e-cigarette users due to their small sample size $(n=2)$, resulting in 944 respondents included in the analyses.

\section{Data analysis}

Means and standard deviations (mean $\pm \mathrm{SD}$ ) were used for continuous variables and frequencies with percentages for categorical variables. Significant differences in variables assessing COVID-19 infection/risk by smoking status were examined by chi-square test for categorical variables and ANOVA for continuous variables. Multinomial logistic regression analysis (Ebrahimi Kalan et al. 2020a) was performed to estimate adjusted odds ratios (aORs) and corresponding 95\% confidence interval (95\% CI) for COVID-19 infection/risk and beliefs surrounding smoking behaviors by smoking status (cigarette, waterpipe, ex-smoker) while controlling for sociodemographic variables: age (years), gender (male/female), education ( $<$ high school/ $>$ high school), and residence area (urban/rural). We excluded dual users from the regression analysis due to the small sample size in each level of covariates. SPSS v.26 and SAS/STATv14.2 were used for all analyses, and the statistical significance was set at $p<0.05$. 
Table 1 Characteristics of the study population based on smoking status $(n=944)$

\begin{tabular}{|c|c|c|c|c|c|c|}
\hline Study characteristics & $\begin{array}{l}\text { Never } \\
\text { smokers }\end{array}$ & $\begin{array}{l}\text { Waterpipe } \\
\text { smokers }\end{array}$ & $\begin{array}{l}\text { Cigarette } \\
\text { smokers }\end{array}$ & Dual $^{\Psi}$ & Ex-smokers & $P$ value* \\
\hline Overall & $511(54.1 \%)$ & $89(9.4 \%)$ & $158(16.7 \%)$ & $14(1.5 \%)$ & $172(18.2 \%)$ & \\
\hline Mean age \pm SD (years) & $35.3 \pm 10.8$ & $35.1 \pm 9.6$ & $38.3 \pm 10.4$ & $33.7 \pm 10.7$ & $35.9 \pm 12.0$ & .042 \\
\hline \multicolumn{7}{|l|}{ Gender } \\
\hline Male & $260(50.9 \%)$ & $62(69.7 \%)$ & $140(88.6 \%)$ & $12(85.7 \%)$ & $127(73.8 \%)$ & \multirow[t]{2}{*}{$<.001$} \\
\hline Female & $251(49.1 \%)$ & $27(30.3 \%)$ & $18(11.4 \%)$ & $2(14.3 \%)$ & $45(26.2 \%)$ & \\
\hline \multicolumn{7}{|l|}{ Education } \\
\hline$\leq$ High school & $93(18.2 \%)$ & $31(34.8 \%)$ & $52(32.9 \%)$ & $5(35.7 \%)$ & $46(26.7 \%)$ & \multirow[t]{2}{*}{$<.001$} \\
\hline$>$ High school & $418(81.8 \%)$ & $58(65.2 \%)$ & $106(67.1 \%)$ & $9(64.3 \%)$ & $126(73.3 \%)$ & \\
\hline \multicolumn{7}{|l|}{ Residential area } \\
\hline Urban & $480(93.9 \%)$ & $72(80.9 \%)$ & $142(89.9 \%)$ & $14(100.0 \%)$ & $149(86.6 \%)$ & \multirow[t]{2}{*}{$<.001$} \\
\hline Nonurban/rural & $31(6.1 \%)$ & $17(19.1 \%)$ & $16(10.1 \%)$ & $0(0.0 \%)$ & $23(13.4 \%)$ & \\
\hline Has a doctor told you that you have COVID-19? (yes) & $17(3.3 \%)$ & $4(4.5 \%)$ & $2(1.3 \%)$ & $2(14.3 \%)$ & $3(1.7 \%)$ & .046 \\
\hline $\begin{array}{l}\text { Is anyone in your family infected with COVID-19? } \\
\text { (yes) }\end{array}$ & $30(5.9 \%)$ & $7(7.9 \%)$ & $7(4.4 \%)$ & $3(21.4 \%)$ & $10(5.8 \%)$ & .129 \\
\hline \multicolumn{7}{|c|}{ In your opinion, how related is cigarette smoking to spreading infection of COVID-19? } \\
\hline Not related/ I do not know & $331(64.8 \%)$ & $76(85.4 \%)$ & $135(85.4 \%)$ & $14(100.0 \%)$ & $122(70.9 \%)$ & \multirow[t]{2}{*}{$<.001$} \\
\hline Related & $180(35.2 \%)$ & $13(14.6 \%)$ & $23(14.6 \%)$ & $0(0.0 \%)$ & $50(29.1 \%)$ & \\
\hline \multicolumn{7}{|c|}{ In your opinion, how related is waterpipe smoking with spreading infection of COVID-19? } \\
\hline Not related/I do not know ${ }^{¥}$ & $233(45.6 \%)$ & $55(61.8 \%)$ & $91(57.6 \%)$ & $13(92.9 \%)$ & $87(50.6 \%)$ & \\
\hline Related & $278(54.4 \%)$ & $34(38.2 \%)$ & $67(42.4 \%)$ & $1(7.1 \%)$ & $85(49.4 \%)$ & \\
\hline \multicolumn{7}{|c|}{ In your opinion, how related is e-cigarette use with spreading infection of COVID-19? } \\
\hline Not related/ I do not know ${ }^{¥}$ & $397(77.7 \%)$ & $86(96.6 \%)$ & $143(90.5 \%)$ & $13(92.9 \%)$ & $145(84.3 \%)$ & \\
\hline Related & $114(22.3 \%)$ & $3(3.4 \%)$ & $15(9.5 \%)$ & $1(7.1 \%)$ & $27(15.7 \%)$ & \\
\hline \multicolumn{7}{|c|}{ In your opinion, how safe is it to use cigarettes at home during the COVID-19 pandemic? } \\
\hline Not safe & $281(55.0 \%)$ & $53(59.6 \%)$ & $60(38.0 \%)$ & $4(28.6 \%)$ & $95(55.2 \%)$ & \multirow[t]{3}{*}{$<.001$} \\
\hline Safe & $85(16.6 \%)$ & $20(22.5 \%)$ & $48(30.4 \%)$ & $6(42.9 \%)$ & $32(18.6 \%)$ & \\
\hline I do not know & $145(28.4 \%)$ & $16(18.0 \%)$ & $50(31.6 \%)$ & $4(28.6 \%)$ & $45(26.2 \%)$ & \\
\hline \multicolumn{7}{|c|}{ In your opinion, how safe is it to use waterpipe at home during the COVID-19 pandemic? } \\
\hline Not safe & $316(61.8 \%)$ & $38(42.7 \%)$ & $68(43.0 \%)$ & $4(28.6 \%)$ & $101(58.7 \%)$ & \multirow[t]{3}{*}{$<.001$} \\
\hline Safe & $87(17.0 \%)$ & $42(47.2 \%)$ & $33(20.9 \%)$ & $5(35.7 \%)$ & $30(17.4 \%)$ & \\
\hline I do not know & $108(21.1 \%)$ & $9(10.1 \%)$ & $57(36.1 \%)$ & $5(35.7 \%)$ & $41(23.8 \%)$ & \\
\hline \multicolumn{7}{|c|}{ In your opinion, how safe is it to use e-cigarettes at home during the COVID-19 pandemic? } \\
\hline Not safe & $232(45.4 \%)$ & $34(38.2 \%)$ & $44(27.8 \%)$ & $2(14.3 \%)$ & $65(37.8 \%)$ & \multirow[t]{3}{*}{$<.001$} \\
\hline Safe & $75(14.7 \%)$ & $13(14.6 \%)$ & $32(20.3 \%)$ & $5(35.7 \%)$ & $28(16.3 \%)$ & \\
\hline I do not know & $204(39.9 \%)$ & $42(47.2 \%)$ & $82(51.9 \%)$ & $7(50.0 \%)$ & $79(45.9 \%)$ & \\
\hline \multicolumn{7}{|c|}{ In your opinion, how safe is it to use cigarettes in public during the COVID-19 pandemic? } \\
\hline Not safe & $371(72.6 \%)$ & $39(43.8 \%)$ & $81(51.3 \%)$ & $10(71.4 \%)$ & $124(72.1 \%)$ & \multirow[t]{3}{*}{$<.001$} \\
\hline Safe & $40(7.8 \%)$ & $34(38.2 \%)$ & $39(24.7 \%)$ & $0(0.0 \%)$ & $13(7.6 \%)$ & \\
\hline I do not know & $100(19.6 \%)$ & $16(18.0 \%)$ & $38(24.1 \%)$ & $4(28.6 \%)$ & $35(20.3 \%)$ & \\
\hline \multicolumn{7}{|c|}{ In your opinion, how safe is it to use waterpipe in public during the COVID-19 pandemic? } \\
\hline Not safe & $402(78.7 \%)$ & $56(63.6 \%)$ & $93(58.9 \%)$ & $7(50.0 \%)$ & $139(80.8 \%)$ & \multirow[t]{3}{*}{$<.001$} \\
\hline Safe & $21(4.1 \%)$ & $23(26.1 \%)$ & $17(10.8 \%)$ & $1(7.1 \%)$ & $7(4.1 \%)$ & \\
\hline I do not know & $88(17.2 \%)$ & $9(10.2 \%)$ & $48(30.4 \%)$ & $6(42.9 \%)$ & $26(15.1 \%)$ & \\
\hline \multicolumn{7}{|c|}{ In your opinion, how safe is it to use e-cigarettes in public during the COVID-19 pandemic? } \\
\hline Not safe & $317(62.0 \%)$ & $34(38.2 \%)$ & $59(37.3 \%)$ & $4(28.6 \%)$ & $112(65.1 \%)$ & \multirow[t]{3}{*}{$<.001$} \\
\hline Safe & $31(6.1 \%)$ & $28(31.5 \%)$ & $29(18.4 \%)$ & $2(14.3 \%)$ & $12(7.0 \%)$ & \\
\hline I do not know & $163(31.9 \%)$ & $27(30.3 \%)$ & $70(44.3 \%)$ & $8(57.1 \%)$ & $48(27.9 \%)$ & \\
\hline
\end{tabular}


Table 1 (continued)

\begin{tabular}{|c|c|c|c|c|c|c|}
\hline Study characteristics & $\begin{array}{l}\text { Never } \\
\text { smokers }\end{array}$ & $\begin{array}{l}\text { Waterpipe } \\
\text { smokers }\end{array}$ & $\begin{array}{l}\text { Cigarette } \\
\text { smokers }\end{array}$ & Dual $^{\Psi}$ & Ex-smokers & $P$ value* \\
\hline \multicolumn{7}{|c|}{ In your opinion, how much safer are e-cigarettes as a substitute to any form of smoking during the COVID-19 pandemic? } \\
\hline Not safe/I do not know ${ }^{¥}$ & $499(97.7 \%)$ & $87(97.8 \%)$ & $150(94.9 \%)$ & $12(85.7 \%)$ & $169(98.3 \%)$ & \multirow[t]{2}{*}{.030} \\
\hline Safe & $12(2.3 \%)$ & $2(2.2 \%)$ & $8(5.1 \%)$ & $2(14.3 \%)$ & $3(1.7 \%)$ & \\
\hline \multicolumn{7}{|c|}{ In your opinion, what will be the outcome of a cigarette smoker who is infected by COVID-19? } \\
\hline Similar to non-smokers & $97(19.0 \%)$ & $27(30.3 \%)$ & $47(29.7 \%)$ & $7(50.0 \%)$ & $34(19.8 \%)$ & \multirow[t]{3}{*}{$<.001$} \\
\hline Recover soon & $13(2.5 \%)$ & $14(15.7 \%)$ & $9(5.7 \%)$ & $1(7.1 \%)$ & $2(1.2 \%)$ & \\
\hline Worsen the disease & $401(78.5 \%)$ & $48(53.9 \%)$ & $102(64.6 \%)$ & $6(42.9 \%)$ & $136(79.1 \%)$ & \\
\hline \multicolumn{7}{|c|}{ In your opinion, what will be the outcome of a hookah smoker who is infected by COVID-19? } \\
\hline Similar to non-smokers & $96(18.8 \%)$ & $24(27.0 \%)$ & $52(32.9 \%)$ & $8(57.1 \%)$ & $32(18.6 \%)$ & \multirow[t]{3}{*}{$<.001$} \\
\hline Recover soon & $8(1.6 \%)$ & $18(20.2 \%)$ & $4(2.5 \%)$ & $1(7.1 \%)$ & $2(1.2 \%)$ & \\
\hline Worsen the disease & $407(79.6 \%)$ & $47(52.8 \%)$ & $102(64.6 \%)$ & $5(35.7 \%)$ & $138(80.2 \%)$ & \\
\hline \multicolumn{7}{|c|}{ In your opinion, what will be the outcome of an e-cigarette user who is infected by COVID-19? } \\
\hline Similar to non-smokers & $225(44.0 \%)$ & $60(67.4 \%)$ & $102(64.6 \%)$ & $9(64.3 \%)$ & $80(46.5 \%)$ & \multirow[t]{3}{*}{$<.001$} \\
\hline Recover soon & $8(1.6 \%)$ & $4(4.5 \%)$ & $3(1.9 \%)$ & $1(7.1 \%)$ & $4(2.3 \%)$ & \\
\hline Worsen the disease & $278(54.4 \%)$ & $25(28.1 \%)$ & $53(33.5 \%)$ & $4(28.6 \%)$ & $88(51.2 \%)$ & \\
\hline \multicolumn{7}{|c|}{ Does using tobacco products protect an individual against COVID-19? } \\
\hline Not only is not protective, but also can cause disease & $387(75.7 \%)$ & $49(55.1 \%)$ & $101(63.9 \%)$ & $8(57.1 \%)$ & $136(79.1 \%)$ & \multirow[t]{3}{*}{$<.001$} \\
\hline Yes, have a protective effect & $21(4.1 \%)$ & $23(25.8 \%)$ & $14(8.9 \%)$ & $4(28.6 \%)$ & $9(5.2 \%)$ & \\
\hline I do not know & $103(20.2 \%)$ & $17(19.1 \%)$ & $43(27.2 \%)$ & $2(14.3 \%)$ & $27(15.7 \%)$ & \\
\hline
\end{tabular}

*Note: due to very low total number of participants answered "I don't know" to these questions, we combined this response option with not related/safe. $\Psi$ Dual use of waterpipe and cigarette smokers. *P-values are based on chi-squared test.

\section{Results and discussion}

\section{General characteristics of the study participants}

The study participants $(N=944$; mean age $\pm \mathrm{SD}=35.3 \pm 10.8$ years) were largely male (64\%), had $>$ high school education (76\%), and most were urban residents $(91 \%)$. Never smokers were almost equally distributed by gender, but waterpipe $(70 \%)$, cigarette $(89 \%)$, and dual smokers $(86 \%)$ and exsmokers $(74 \%)$ were mostly male. Three percent $(n=28)$ of the study population were infected with COVID-19 at the time of the study, and $6 \%(n=57)$ had a family member with COVID-19. As shown in Fig. 1, of the 172 ex-smokers, 78 (45.3\%) quit due to concerns of COVID-19 and will continue even after the pandemic, 16 (9.4\%) quit due to COVID-19 and will resume after this pandemic, and $78(45.3 \%)$ quit due to reasons other than COVID-19

\section{Beliefs regarding COVID-19 infection/risk and smoking behaviors}

As shown in Table 1, Fig. 2 less than a third (29.1\%) of all respondents believed that cigarette smoking was related to spreading COVID-19 infection, while almost half (49.4\%) believed that waterpipe smoking was related to spreading COVID-19 infection. Only 17\% of all respondents believed that e-cigarette use was related to spreading COVID-19 infection. Never-smokers were more likely than tobacco users to believe that smoking cigarettes or waterpipe at home or in public is not safe. More than half of participants (smokers and never-smokers) believed that tobacco smoking was not protective against COVID-19 and that it could aggravate the infection.

\section{Results of the regression analysis}

Multinomial logistic regression analysis (Table 2) showed aORs for beliefs surrounding COVID-19 infection/risk and smoking behaviors among waterpipe and cigarette smokers compared with never smokers (reference). Cigarette smokers $(\mathrm{aOR}=0.49,95 \% \mathrm{CI} 0.26-0.91)$ were less likely to believe that smoking cigarettes was related to COVID-19 infection.

Waterpipe smokers $(\mathrm{aOR}=7.19,95 \%$ CI $3.01-17.14)$ were more likely to believe that smoking waterpipe at home is safe during the COVID-19 pandemic. Using e-cigarettes in public places was believed to be safe during the COVID-19 pandemic among both waterpipe $(\mathrm{aOR}=3.01,95 \%$ CI 1.25 $7.29)$ and cigarette $(\mathrm{aOR}=3.56,95 \%$ CI $1.02-12.46)$ smokers. Waterpipe smokers were more likely to believe that smoking waterpipe $(\mathrm{aOR}=29.98,95 \%$ CI $4.15-216.55)$ would lead to rapid recovery if they were infected with COVID-19. Cigarette smokers were more likely to believe 
Fig. 1 Reasons for quitting smoking waterpipe/cigarettes among smokers $(n=172)$

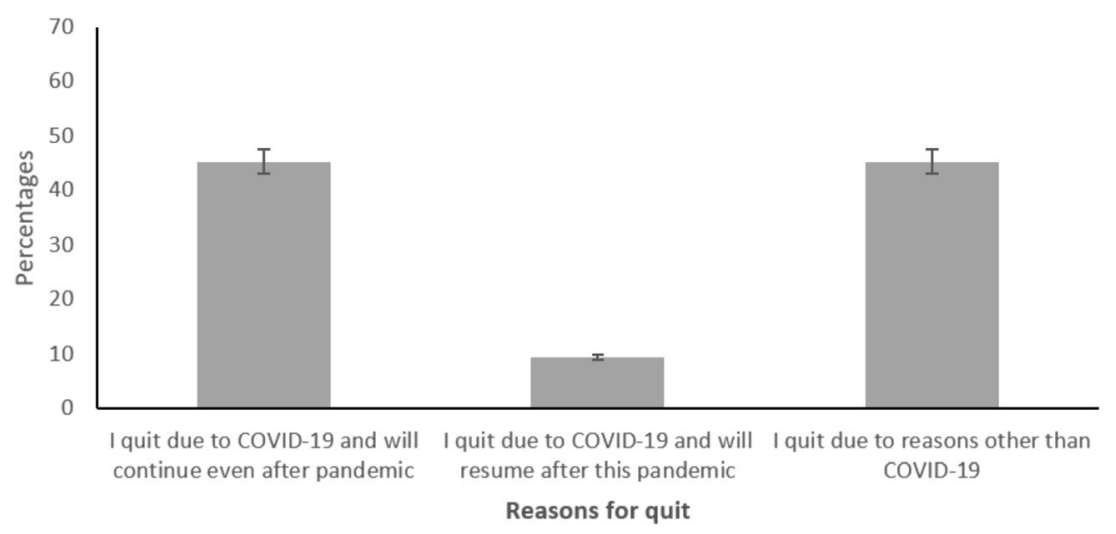

that if an e-cigarette user was infected with COVD-19, their condition will be like a non-e-cigarette user or even better $(\mathrm{aOR}=0.53,95 \%$ CI $0.31-0.91)$. Waterpipe smokers were more likely to believe that smoking waterpipe can protect against COVID-19 infection (aOR $=4.10,95 \%$ CI $1.53-$ 10.96).

Our study highlighted important differences in beliefs surrounding COVID-19 infection/risk by smoking status. Key findings of this study are that compared with never-smokers, (1) cigarette smokers were less likely to believe that smoking cigarette can lead to spreading COVID-19; (2) waterpipe smokers were more likely to believe that smoking waterpipe at home was a safe practice, may lead to a more rapid recovery if they were infected with COVID-19, and can have a protective effect against COVID-19 infection; (3) both waterpipe and cigarette smokers believed that using e-cigarettes in public places was a safe practice during the COVID-19 pandemic; and (4) more than half of the ex-smokers stopped smoking due to COVID-19 and most of them planned to continue abstaining from smoking after the pandemic. Although the evidence regarding the relationship between tobacco smoking and COVID-19 infection/progression is limited, our findings underscore the need to raise awareness about the unsupported claims of a lower hazard of using tobacco products or possible protective effects against COVID-19 among tobacco users and to promote continued cessation among those stopped smoking during the pandemic.

With easy access to social platforms, a high volume of unsubstantial information (with a lot of misleading conclusions) can circulate among the general population and influence their general beliefs and behaviors. Iran is no exception, and the finding in our study that waterpipe smokers believe that smoking waterpipe can have a protective effect against contracting COVID-19 infection, and cigarette smokers believing that smoking cigarettes cannot lead to spreading COVID-19, may have been influenced by what is being shared on these platforms. Laymen often share results of studies that reported lower smoking prevalence among patients with COVID-19 (De Lusignan et al. 2020; Farsalinos et al. 2020). These studies may have failed to address sources of errors (e.g., differential access to care by smoking status, prioritizing care for less severe cases, or those with lower comorbidities likely among never-smokers).

Given the pervasiveness of waterpipe smoking in Iran, it is troubling that in our study so many smokers had
Fig. 2 Relation of tobacco products use and spreading COVID-19 infection $(n=944)$

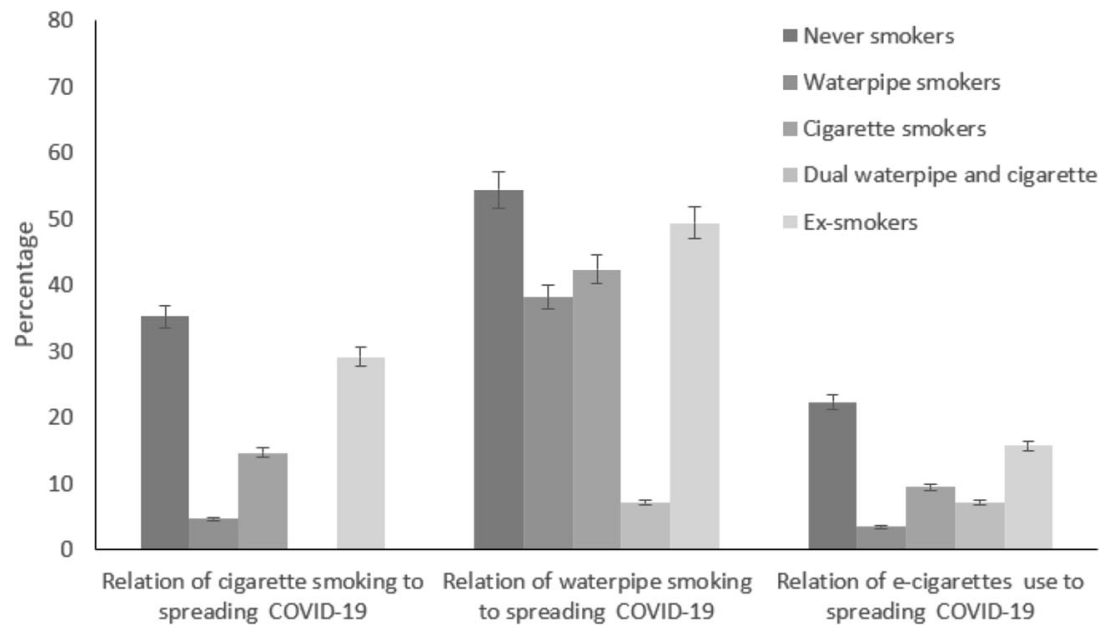


Table 2 Multinomial logistic regression ${ }^{\ddagger}$ of factors associated with COVID-19 and smoking status $(n=930)^{\Psi}$

\begin{tabular}{|c|c|c|c|}
\hline COVID-19 related factors & $\begin{array}{l}\text { Cigarette smokers } \\
\text { aOR }(95 \% \mathrm{CI})\end{array}$ & $\begin{array}{l}\text { Waterpipe smokers } \\
\text { aOR }(95 \% \mathrm{CI})\end{array}$ & $\begin{array}{l}\text { Ex-smokers } \\
\text { aOR }(95 \% \mathrm{CI})\end{array}$ \\
\hline Has a doctor told you that you have COVID-19? (yes) & $0.36(0.06-2.01)$ & $2.92(0.76-11.18)$ & $0.53(0.14-1.92$ \\
\hline Is anyone in your family infected with COVID-19? (yes) & $0.69(0.26-1.84)$ & $0.71(0.21-2.38)$ & $0.92(0.39-2.19$ \\
\hline
\end{tabular}

In your opinion, how related is cigarette smoking to spreading infection of COVID-19?

Not related/I do not know

Related

Reference

$0.49(0.26-0.91) *$

In your opinion, how related is waterpipe smoking with spreading infection of COVID-19?

Not related/I do not know

Reference

Related

$1.03(0.62-1.69)$

In your opinion, how related is e-cigarette use with spreading infection of COVID-19?

Not related/I do not know

Reference

Related

$0.95(0.44-2.05)$

In your opinion, how safe is it to use cigarettes at home during the COVID-19 pandemic?

Not safe

Safe

Reference

I do not know

$1.59(0.80-3.16)$

$0.53(0.24-1.16)$

In your opinion, how safe is it to use waterpipe at home during the COVID-19 pandemic?

Not safe

Reference

Safe

$0.95(0.45-2.01)$

I do not know

$2.98(1.21-7.34) *$

In your opinion, how safe is it to use e-cigarettes at home during the COVID-19 pandemic?

Not safe

Safe

Reference

$0.84(0.37-1.94)$

I do not know

$0.82(0.38-1.74)$

In your opinion, how safe is it to use cigarettes in public during the COVID-19 pandemic?

Not safe

Reference

Safe

$1.79(0.81-3.92)$

I do not know

$0.52(0.20-1.31)$

In your opinion, how safe is it to use waterpipe in public during the COVID-19 pandemic?

Not safe

Reference

Safe

$0.62(0.22-1.75)$

$1.88(0.69-5.16)$

I do not know

In your opinion, how safe is it to use e-cigarettes in public during the COVID-19 pandemic?

Not safe

Reference

$3.01(1.25-7.29) *$

$1.32(0.62-2.80)$

I do not know

In your opinion, how much safer are e-cigarettes as a substitute to any form of smoking during the

Not safe/I do not know

Reference

$1.54(0.51-4.62)$

Safe

In your opinion, what will be the outcome of a cigarette smoker who is infected by COVID-19?

Similar to non-smokers

Reference

$0.97(0.24-3.95)$

Recover soon

$0.84(0.33-2.17)$

Worsen the disease

who is infected by COVID-19?

Similar to non-smokers

Reference

$0.76(0.10-5.68)$

$1.10(0.41-2.98)$

Worsen the disease

In your opinion, what will be the outcome of an e-cigarette user who is infected by COVID-19?
Reference

$0.97(0.42-2.25)$

Reference

$0.59(0.30-1.16)$

Reference

$0.31(0.08-1.31)$

Reference

$0.39(0.15-1.01)$

$0.33(0.12-0.91) *$

Reference

$7.19(3.01-17.14) *$

$0.88(0.25-3.12)$

Reference

$0.09(0.03-0.29)$

$0.96(0.41-2.26)$

Reference

2.44 (0.77-7.70)

$3.32(1.06-10.42) *$

Reference

$1.19(0.34-4.14)$

$0.39(0.10-1.44)$

Reference

$3.56(1.02-12.46) *$

0.87 (0.34-2.23)

\section{Reference}

$1.48(0.22-10.03)$

Reference

$0.19(0.03-1.27)$

$0.55(0.17-1.79)$

Reference

$29.98(4.15-216.55) *$

$1.20(0.34-4.18)$
Reference

0.97 (0.59-1.59)

Reference

0.87 (0.56-1.35)

Reference

$0.75(0.41-1.38)$

Reference

$0.99(0.51-1.93)$

$0.52(0.26-1.02)$

Reference

$0.96(0.47-1.93)$

$1.47(0.68-3.20)$

Reference

$1.14(0.55-2.40)$

$1.79(0.94-3.42)$

Reference

$1.01(0.42-2.42)$

$2.00(0.90-4.41)$

Reference

$0.71(0.22-2.35)$

$0.65(0.25-1.67)$

Reference

$0.94(0.36-2.43)$

$0.54(0.28-1.06)$

Reference

$0.73(0.19-2.80)$

Reference

$0.24(0.03-2.03)$

$0.85(0.35-2.08)$

Reference

0.89 (0.07-10.95)

$1.26(0.48-3.32)$ 
Table 2 (continued)

\begin{tabular}{llll}
\hline COVID-19 related factors & $\begin{array}{l}\text { Cigarette smokers } \\
\text { aOR }(95 \% \mathrm{CI})\end{array}$ & $\begin{array}{l}\text { Waterpipe smokers } \\
\text { aOR }(95 \% \mathrm{CI})\end{array}$ & $\begin{array}{l}\text { Ex-smokers } \\
\text { aOR }(95 \% \mathrm{CI})\end{array}$ \\
\hline Similar to non-e-cigarette users & Reference & $\begin{array}{l}\text { Refence } \\
0.11(0.02-0.70)\end{array}$ & $\begin{array}{l}1.88(0.37-9.63) \\
\text { Recover soon }\end{array}$ \\
Worsen the disease & $0.38(0.06-2.44)$ & $0.54(0.26-1.11)$ & $0.77(0.48-1.23)$ \\
Does using tobacco products protect an individual against COVID-19? & $0.53(0.31-0.91)^{*}$ & Reference & Reference \\
Not only is not protective, but also can cause disease & Reference & $4.10(1.53-10.96) *$ & $1.34(0.53-3.41)$ \\
Yes, have a protective effect & $1.57(0.63-3.88)$ & $1.15(0.50-2.63)$ & $0.63(0.34-1.14)$ \\
I do not know & $0.82(0.45-1.52)$ & \\
\hline
\end{tabular}

${ }^{¥}$ Reference group is never-smokers, ${ }^{\Psi}$ We excluded dual users $(n=14)$ from the regression analysis due to the small sample size in each level of covariates. Asterisk indicates $p<0.05$. The regression model was adjusted for potential confounders including age (years), gender (male/female), education ( $<$ high school $>$ high school), and residence area (urban/rural)

$a O R$ adjusted odds ratio, $C I$ confidence interval

misperceptions about waterpipe risks. Nearly half of waterpipe smokers believed that smoking at home during the pandemic is safe. However, home use (vs. smoking in cafes) is unlikely to mitigate risks that come from smoking in close proximity to others and sharing waterpipe apparatus, which promotes microbial spread (Altindis et al. 2020). Also, worrying is that about 1 in 4 waterpipe smokers have unsupported - and likely incorrect - notions that waterpipe smoking protects against acquiring COVID-19 and will hasten recovery for those who do acquire it. These perceptions are likely to enhance infection risk not only to waterpipe smokers but to non-smokers with whom they interact. These misconceptions may stem from existing beliefs of the safety of waterpipe smoking in Iran and the Middle East in general (Akl et al. 2013; Ozouni Davaji et al. 2017).

Previously, we highlighted the importance of restricting waterpipe-serving venues to contain COVID-19 pandemic (Ebrahimi Kalan et al. 2020b, c). Doing so is important during this time of pandemic because waterpipe cafés are an important source of exposure to PM2.5 which increases the risk of respiratory and cardiovascular disease among waterpipe smokers (Bhatnagar et al. 2019; Naddafi et al. 2019c). Preliminary reports show that small increases in long-term exposure to PM2.5 lead to a large increase in the COVID-19 death rate (Wu et al. 2020). Therefore, the concentration of pollutants (which may include this novel coronavirus) in the indoor air of underground smoking cafés in Tehran and other cities with high rate of COVID-19 infection may pose serious risks for the health of both personnel and patrons and upsurge the burden on healthcare providers in tackling with COVID19 outbreak. While government efforts have been somewhat successful, current reports from Tehran's Police Department (News) show that some underground waterpipe cafes are serving waterpipe to their customers during this pandemic despite their closing orders and not being included in any phases of reopening in Iran's capital as of August 5, 2020 (Dunyaye
Eghtesad News 2020; IRIB News Agency. Prohibition of hookah use in coffee shops 2020).

Although government regulation can prevent COVID-19 exposure in waterpipe-serving venues, the problem is much more intractable in the home environment, especially given that nearly half of waterpipe smokers in our study believed that smoking at home is safe. Further, the problem has become even more pervasive due to burgeoning waterpipe-home delivery services that have developed in response to café closings (Ebrahimi Kalan et al. 2020d; BaharNews 2020). Mass media and social media campaigns are needed to educate smokers about evidence-based association between smoking and progression in COVID-19 and encourage quitting. In this regard, it is reassuring that among our study participants, half of the ex-smokers quit in response to concerns about COVID19 and planned to stay quit after the pandemic.

Some limitations are notable in this study. Respondents had to have access to the internet and mobile/computer literacy to complete the survey. Nonetheless, Telegram is the most popular social media platform in Iran with more than 50 million active users, which represent more than $60 \%$ of the population (Ghaffari et al. 2017; Wikipedia 2020). The cross-sectional nature of this study limits cause-effect relationships. The results yielded a wide 95\% CI for the question "In your opinion, what will be the outcome of a waterpipe smoker who is infected by COVID-19?" should be interpreted with caution regardless of statistical significance.

The lessons learned over the past half a century show that smoking has detrimental health effects on the structure and function of the respiratory systems and lessens lung defenses against infection (DHHS 2014; Loddenkemper et al. 2015). Nevertheless, the issue of tobacco product use and risk of contracting COVID-19 infection is still topical (Van ZylSmit et al. 2020) and necessitate future nationwide population-based studies to provide a clear picture of this 
issue, especially in the developing countries that comprise $80 \%$ of smokers populations globally.

\section{Conclusion}

The present study from an epicenter of COVID-19 in the Middle East shows the importance of promoting smoking cessation, discouraging sharing of waterpipes and smoking at home, and enforcing public policy such as closure of waterpipe venues. Such efforts are likely to help stop the spread of SARS-CoV-2 and protect smokers and nonsmokers alike from exposure and consequences if exposed.

Acknowledgments We gratefully acknowledge Ardabil University of Medical Sciences. Also, we thank all participants for completing this online survey.

Authors' contributions Mohammad Ebrahimi Kalan and Davoud Adham participated in the conceptualization and design of the research and supervised the work. Hassan Ghobadi and Mehdi Fazlzadeh involved in data collection. Ziyad Ben Taleb and Caroline $\mathrm{O}$ are responsible for analysis and interpretation of data. Mohammad Ebrahimi Kalan, Mehdi Fazlzadeh, and Kenneth D Ward wrote the first draft of manuscript. Raed Behaleh Contributet to final editing of manuscript. All authors have read and approved the final paper as submitted.

Funding This research work was financially supported by Ardabil University of Medical Sciences,

Data availability The data used and analyzed during the current study are available from the corresponding author upon reasonable request.

\section{Compliance with ethical standards}

Conflict of interest The authors declare that they have no conflict of interest.

Ethical consideration The protocol was approved by the Institutional Review Board of Ardabil University of Medical Sciences (Approval ID: IR.ARUMS.REC.1399.120).

Consent to participate Not applicable.

Consent to publish All the authors agreed to publish the data in this journal.

\section{References}

Akl EA, Jawad M, Lam WY et al (2013) Motives, beliefs and attitudes towards waterpipe tobacco smoking: a systematic review. Harm Reduct J 10:12. https://doi.org/10.1186/1477-7517-10-12

Al Mulla A, Fanous N, Seidenberg AB et al (2015) Secondhand smoke emission levels in waterpipe cafes in Doha. Qatar Tob Control 24: e227-e231. https://doi.org/10.1136/tobaccocontrol-2014-051717

Altindis M, Koroglu M, Demiray T et al (2020) Microbial contamination and infection risks of narghile besides hazards of tobacco. Cent Eur J Public Health 28:74-78. https://doi.org/10.21101/cejph.a5814
BaharNews B (2020) We bring hookah to your home on Corona days. http://www.baharnews.ir/news/213979/

Bhatnagar A, Maziak W, Eissenberg T et al (2019) Water Pipe (Hookah) Smoking and cardiovascular disease risk: a scientific statement from the American Heart Association Circulation 139:e917-e936 https:// doi.org/10.1161/cir.0000000000000671

Cobb CO, Vansickel AR, Blank MD et al (2013) Indoor air quality in Virginia waterpipe cafes. Tob Control 22:338-343. https://doi.org/ 10.1136/tobaccocontrol-2011-050350

De Lusignan S, Dorward J, Correa A et al (2020) Risk factors for SARSCoV-2 among patients in the Oxford Royal College of General Practitioners Research and Surveillance Centre primary care network: a cross-sectional study. Lancet Infect Dis. https://doi.org/10. 1016/s1473-3099(20)30371-6

DHHS U (2014) The Health consequences of smoking - 50 years of progress. A report of the surgeon general. Atlanta, GA: US DHHS, Cent. Dis. Control Prev., Natl. Cent. Chronic Dis. Prev. Health Promot., Off. Smok. Health

Dunyaye Eghtesad News (2020) Police alert to underground cafes. https://donya-e-eqtesad.com/

Ebrahimi Kalan M, Jebai R, Zarafshan E et al (2020a) Distinction between two statistical terms: multivariable and multivariate logistic regression. Nicotine Tob Res. https://doi.org/10.1093/ntr/ntaa055

Ebrahimi Kalan M, Ben Taleb Z, Fazlzadeh M, Ward KD, Maziak W (2020b) Waterpipe tobacco smoking: a potential conduit of COVID19

Ebrahimi Kalan M, Ghobadi H, Taleb ZB et al (2020c) Descriptive characteristics of hospitalized adult smokers and never-smokers with COVID-19. Tob Induc Dis 18:46-46. https://doi.org/10.18332/tid/ 122759

Ebrahimi Kalan M, Rahman A, Gautam P et al (2020d) Hookah home delivery: an emerging public health issue. Tob Control. https://doi. org/10.1136/tobaccocontrol-2019-055327

El-Zaatari ZM, Chami HA, Zaatari GS (2015) Health effects associated with waterpipe smoking Tobacco Control. https://doi.org/10.1136/ tobaccocontrol-2014-051908

Farsalinos K, Barbouni A, Niaura R (2020) Systematic review of the prevalence of current smoking among hospitalized COVID-19 patients in China: could nicotine be a therapeutic option? Internal and emergency medicine:1-8. https://doi.org/10.1007/s11739-02002355-7

Fazlzadeh M, Rostami R, Hazrati S et al (2015) Concentrations of carbon monoxide in indoor and outdoor air of Ghalyun cafes Atmospheric Pollution Research 6:550-555 https://doi.org/10.5094/APR.2015. 061

Ghaffari M, Rakhshanderou S, Mehrabi Y et al (2017) Using social network of telegram for education on continued breastfeeding and complementary feeding of children among mothers: a successful experience from Iran 5:5275-5286

Hessami Z, Masjedi MR, Sharifi H et al (2016) Waterpipe tobacco smoking prevalence and its related factors among Iranian population. Eur Respir J 48:PA4607. https://doi.org/10.1183/13993003. congress-2016.PA4607

IRIB News Agency. Prohibition of hookah use in coffee shops. (2020). https://www.iribnews.ir/fa/news/2657002/.

Kumar SR, Davies S, Weitzman M et al (2015) A review of air quality, biological indicators and health effects of second-hand waterpipe smoke exposure Tob Control 24 Suppl 1:i54-i59 https://doi.org/10. 1136/tobaccocontrol-2014-052038

Loddenkemper R, Kreuter M, Herth F (2015) The tobacco epidemic. Karger

Moosazadeh M, Ziaaddini H, Mirzazadeh A et al (2013) Meta-analysis of smoking prevalence in Iran Addiction \& health 5:140-153

Naddafi K, Nabizadeh R, Baghani AN et al (2019a) Bioaerosols in the waterpipe cafés: genera, levels, and factors influencing their 
concentrations. Environ Sci Pollut Res 26:20297-20307. https://doi. org/10.1007/s11356-019-05413-6

Naddafi K, Nabizadeh R, Rostami R, Ghaffari HR, Fazlzadeh M (2019b) Formaldehyde and acetaldehyde in the indoor air of waterpipe cafés: measuring exposures and assessing health effects. Build Environ 165:106392. https://doi.org/10.1016/j.buildenv.2019.106392

Naddafi K, Nabizadeh R, Rostamy R et al (2019c) Indoor air quality in waterpipe cafés: exposure level to particulate matter. Environ Sci Pollut Res. https://doi.org/10.1007/s11356-019-05546-8

Ozouni Davaji RB, Dadban Shahamat Y, Hajili Davaji F et al (2017) Patterns, beliefs, norms and perceived harms of Hookah smoking in North Iran Asian Pacific journal of cancer prevention : APJCP 18: 823-830 https://doi.org/10.22034/APJCP.2017.18.3.823

Patanavanich R, Glantz SA (2020) Smoking is associated with COVID19 progression: a meta-analysis nicotine $\&$ tobacco research. https:// doi.org/10.1093/ntr/ntaa082

Rostami R, Zarei A, Saranjam B, Ghaffari HR, Hazrati S, Poureshg Y, Fazlzadeh M (2019) Exposure and risk assessment of PAHs in indoor air of waterpipe cafés in Ardebil. Iran Buildi Environ 155:4757. https://doi.org/10.1016/j.buildenv.2019.03.031

Rostami R, Naddafi K, Arfaeinia H, Nazmara S, Fazlzadeh M, Saranjam B (2020) The effects of ventilation and building characteristics on indoor air quality in waterpipe cafés. J Expo Sci Environ Epidemiol 30:805-813. https://doi.org/10.1038/s41370-020-0240-4

Van Zyl-Smit RN, Richards G, Leone FT (2020) Tobacco smoking and COVID-19 infection The Lancet Respiratory Medicine 8:664-665. https://doi.org/10.1016/s2213-2600(20)30239-3

Wikipedia (2020) Telegram in Iran. https://en.wikipedia.org/wiki/ Telegram_in_Iran. Accessed 4 June 2020

World Health Organization (2020a) Smoking and COVID-19. Scientific Brief https://www.who.int/news-room/commentaries/detail/ smoking-and-covid-19. Accessed 4 June 2020

World Health Organization (2020b) Eastern Mediterranean Region. Tobacco free initiative. Tobacco and waterpipe use increases the risk of COVID-19. http://www.emro.who.int/tfi/know-the-truth/ tobacco-and-waterpipe-users-are-at-increased-risk-of-covid-19infection.html. Accessed 8 Aug 2020

Wu X, Nethery RC, Sabath BM et al (2020) Exposure to air pollution and COVID-19 mortality in the United States

Publisher's note Springer Nature remains neutral with regard to jurisdictional claims in published maps and institutional affiliations. 